\title{
Extracellular Traps Released by Neutrophils from Cats are Detrimental to Toxoplasma gondii Infectivity
}

\author{
Isabela S. Macedo ${ }^{1, \dagger}{ }^{\dagger}$, Marcos V. A. Lima ${ }^{1,+}{ }^{,}$Jéssica S. Souza ${ }^{1}$, Natalia C. Rochael ${ }^{2}$, \\ Pedro N. Caldas ${ }^{3}$, Helene S. Barbosa ${ }^{1}$, Flávio A. Lara ${ }^{4}$, Elvira M. Saraiva ${ }^{2} \mathbb{D}$ and \\ Rafael M. Mariante ${ }^{1, *(D)}$ \\ 1 Laboratório de Biologia Estrutural, Instituto Oswaldo Cruz, Fiocruz, Rio de Janeiro 21040-360, RJ, Brazil; \\ macedos.isa@gmail.com (I.S.M.); marquinhos9796@gmail.com (M.V.A.L.); jsouza.biomed@gmail.com (J.S.S.); \\ helene@ioc.fiocruz.br (H.S.B.) \\ 2 Laboratório de Imunobiologia das Leishmanioses, Instituto de Microbiologia Paulo de Góes, \\ Universidade Federal do Rio de Janeiro, Rio de Janeiro 21941-902, RJ, Brazil; \\ natyrochael@yahoo.com.br (N.C.R.); esaraiva@micro.ufrj.br (E.M.S.) \\ 3 HVN Hospital Veterinário Niterói, Niterói 24360-440, RJ, Brazil; pedrovet@pedrovet.com.br \\ 4 Laboratório de Microbiologia Celular, Instituto Oswaldo Cruz, Fiocruz, Rio de Janeiro 21040-360, RJ, Brazil; \\ flavioalveslara2000@gmail.com \\ * Correspondence: rafael.mariante@ioc.fiocruz.br or rafaelmariante@gmail.com; Tel.: +55-21-2562-1018 \\ + These authors contributed equally to this work.
}

Received: 14 September 2020; Accepted: 11 October 2020; Published: 22 October 2020

\begin{abstract}
Toxoplasma gondii is the causative agent of toxoplasmosis, an infectious disease that affects over $30 \%$ of the human world population, causing fatal infections in immunocompromised individuals and neonates. The life cycle of T. gondii is complex, and involves intermediate hosts (birds and mammals) and definitive hosts (felines, including domestic cats). The innate immune repertoire against the parasite involves the production of neutrophil extracellular traps (NET), and neutrophils from several intermediate hosts produce NET induced by T. gondii. However, the mechanisms underlying NET release in response to the parasite have been poorly explored. Therefore, the aims of this study were to investigate whether neutrophils from cats produce NET triggered by T. gondii and to understand the mechanisms thereby involved. Neutrophils from cats were stimulated with $T$. gondii tachyzoites and NET-derived DNA in the supernatant was quantified during the time. The presence of histone $\mathrm{H} 1$ and myeloperoxidase was detected by immunofluorescence. We observed that cat neutrophils produce both classical and rapid/early NET stimulated by T. gondii. Inhibition of elastase, intracellular calcium, and phosphatidylinositol 3-kinase (PI3K)- $\delta$ partially blocked classical NET release in response to the parasite. Electron microscopy revealed strands and networks of DNA in close contact or completely entrapping parasites. Live imaging showed that tachyzoites are killed by NET. We conclude that the production of NET is a conserved strategy to control infection by T. gondii amongst intermediate and definitive hosts.
\end{abstract}

Keywords: calcium; definitive host; elastase; felid; infectivity; killing; live imaging; neutrophil extracellular trap; PI3K; Toxoplasma gondii

\section{Introduction}

Toxoplasma gondii is an obligate intracellular protozoan parasite of the phylum Apicomplexa, and one of the most successful eukaryotic pathogens of medical and veterinary importance, since it can naturally infect all warm-blooded animals, including humans [1,2]. The parasite is distributed worldwide, and it is estimated that one third of the world's human population is chronically infected with T. gondii, with a seroprevalence varying from $9 \%$ to more than $80 \%$ in different countries [3]. 
Humans acquire infection by ingesting contaminated food or water, consuming raw or undercooked meat containing the parasite, or by vertical transmission from mother to fetus [1,2]. In general, the clinical signs produced by $T$. gondii are mild and self-limiting in healthy individuals, but in some cases, it can lead to ocular toxoplasmosis [4]. On the other hand, in immunocompromised individuals and congenitally infected individuals the parasite can lead to severe illness $[5,6]$.

The life cycle of T. gondii is complex, and the parasite can virtually infect all mammals and birds, that are intermediate hosts of the protozoan. Felids are the only known definitive host, in the gut of which the sexual cycle of the parasite occurs giving rise to the environmentally resistant oocysts $[1,2]$. The oocysts are released in cat feces and will mature in the environment, becoming a source of infection for other hosts [7]. Other forms of the parasite include the tachyzoites, which are the fast replicating forms that are vertically transmitted to fetus in congenital toxoplasmosis, and bradyzoites, which are present in tissue cysts and preferentially persist in brain and muscle tissues of infected hosts [8].

Neutrophils are the most abundant white blood cells in cats [9]. They constitute the first line of defense against invading pathogens and modulate adaptive immune responses by interacting with other immune cells through direct cell-to-cell contact [10] and the secretion of immunomodulators [11-13]. During T. gondii infection, neutrophils are rapidly recruited to the site of parasites entry [14-16], where they can get infected, therefore acting as motile reservoirs of T. gondii and contributing to the spread of the parasite through a Trojan-horse mechanism [16].

Neutrophils use an arsenal of weapons against invading microorganisms, including phagocytosis, degranulation, and production of extracellular traps [17-20]. Neutrophil extracellular traps (NET) are composed of a scaffold of DNA associated with granular and cytoplasmic proteins that can entrap and kill pathogens through two major mechanisms: a classical one, which is reactive oxygen species (ROS)-dependent and occurs after 1-4 h of stimulation, leading to neutrophil death; an early/rapid one, which does not depend on ROS and occurs within 5 to 15 min of stimulation, not affecting neutrophil viability and function [21-23].

Release of NET can be triggered by an uncountable number of biological stimuli, including bacteria, fungus, viruses, helminths, and protozoans such as the pathogenic parasite T. gondii [24-28]. Neutrophils from different organisms release NET upon interaction with T. gondii, including those of mice, humans, dogs, cattle, sheep, donkey, harbor seals, and dolphins [29-35], all of which are intermediate hosts for the parasite. Recently, extracellular traps were also shown to be produced by cat neutrophils [36]. However, the mechanisms behind NET formation in response to T. gondii are not completely understood.

Here, we show that neutrophils from cat, the main definitive host for the parasite, release NET in response to two of the major clonal lineages of $T$. gondii and that the parasites are entrapped and killed by NET. The release of NET begins as early as $15 \mathrm{~min}$ of interaction with parasites, and proceeds for several hours, suggesting the existence of both a rapid/early and a classical mechanism of NET production. Classical release of NET does not require infection of neutrophils, and does partially depend on elastase, intracellular calcium, and phosphatidylinositol 3-kinase (PI3K)- $\delta$, but not on myeloperoxidase, peptidyl arginine deiminase (PAD)-4, and PI3K $\gamma$.

Taken together, the data presented here allow us to speculate that the release of extracellular traps in response to T. gondii is a mechanism of the innate immunity to control infection conserved from intermediate to definitive hosts of the parasite.

\section{Materials and Methods}

\subsection{Reagents}

RPMI 1640 culture medium and fetal calf serum were obtained from Cultilab (Campinas, SP, Brazil). Ficoll Paque Plus was obtained from GE Healthcare (Chicago, IL, USA). DMEM/F12 culture medium was acquired from Gibco (Thermo Fisher Scientific, Waltham, MA, USA). Propidium iodide and penicillin-streptomycin antibiotics were obtained from Sigma-Aldrich (St. Louis, MO, USA). Quant-iT 
PicoGreen dsDNA Assay Kit, ProLong Diamond Antifade Mountant with DAPI, and PrestoBlue Cell Viability Reagent were acquired from Invitrogen (Thermo Fisher Scientific, Waltham, MA, USA).

We used the following pharmacological inhibitors/inducers in the study: phorbol 12-myristate 13-acetate (PMA; 100 nM; Sigma-Aldrich), DNase (20 U/mL; Invitrogen), cytochalasin D (CytD; $10 \mu \mathrm{g} / \mathrm{mL}$; Sigma-Aldrich), elastase inhibitor III (ELi; MeOSuc-AAPV-CMK; $10 \mu \mathrm{g} / \mathrm{mL}$; Calbiochem, San Diego, CA, USA), myeloperoxidase inhibitor I (MPOi; 600 nM; Calbiochem), AS605240 (selective inhibitor of PI3K $\gamma ; 10 \mu \mathrm{M}$; Tocris Bioscience, Bristol, UK), IC87114 (selective inhibitor of PI3K $\delta$; $1 \mu \mathrm{M}$; Cayman Chemical, Ann Arbor, MI, USA), chloroamidine (Cl-A; PAD inhibitor; $12 \mu \mathrm{M}$; Cayman Chemical); PD98059 (MEK inhibitor; $60 \mu \mathrm{M}$; Sigma-Aldrich) and BAPTA/AM ([Ca ${ }^{2+}$ ]i chelator; $10 \mu \mathrm{M}$; Calbiochem).

The following antibodies were used in this study: rabbit anti-myeloperoxidase polyclonal (PA5-16672; 1:200; Invitrogen), mouse anti-histone H1 monoclonal (sc-8030; 1:100; Santa Cruz Biotechnology, Santa Cruz, CA, USA), mouse anti-toxoplasma (TP3) monoclonal (sc-52255; 1:100; Santa Cruz Biotechnology), Goat anti-Mouse Alexa Fluor 594 (A11032; 1:1600; Invitrogen), and Donkey anti-Rabbit Alexa Fluor 488 (A21206; 1:600; Invitrogen).

\subsection{Animals}

The cats used in this study were all mixed breed, from both sexes, aging from 1 to 6 years old, negative for feline immunodeficiency virus (FIV) and feline leukemia virus (FeLV). The study was carried out in strict accordance with the guidelines of the Oswaldo Cruz Foundation (Fiocruz), the National Council for the Control of Animal Experimentation (CONCEA, Brazil), and the Normative Resolution 30/2016 of the same entity. The blood samples herein used were leftovers from samples taken for the diagnose of animals in need.

\subsection{Isolation of Neutrophils from Cats}

Peripheral blood samples $(\approx 2-4 \mathrm{~mL})$ were provided by the Veterinary Hospital Niterói, RJ. Neutrophils were isolated by density gradient centrifugation using Ficoll Paque Plus (1.077 g/mL). After centrifugation (400× $g$ for $30 \mathrm{~min})$, the neutrophil layer containing red blood cells (RBC) was collected and transferred to a $15 \mathrm{~mL}$ conical tube and suspended in $0.2 \% \mathrm{NaCl}$ for $30 \mathrm{~s}$ for $\mathrm{RBC}$ lysis. Afterwards, an equal amount of $\mathrm{NaCl} \mathrm{1.6 \%} \mathrm{was} \mathrm{added} \mathrm{to} \mathrm{stop} \mathrm{RBC} \mathrm{lysis.} \mathrm{Finally,} \mathrm{cells} \mathrm{were}$ washed, suspended in RPMI 1640 medium supplemented with $1 \%$ fetal calf serum and $1 \%$ penicillinstreptomycin antibiotics solution, and kept on ice until use.

\subsection{Parasites Culture}

Tachyzoites of T. gondii from RH strain are routinely maintained in Swiss mice by intraperitoneal inoculation of parasites, as previously described [37]. After $72 \mathrm{~h}$ of inoculation parasites were harvested from peritoneum in PBS and centrifuged (200× $g$ for $5 \mathrm{~min}$ ) to remove any contaminating cells. The supernatant containing the parasites was transferred to another tube and centrifuged again (1500 $\times g$ for $10 \mathrm{~min})$. Parasites were recovered from pellet, counted in a hemocytometer, and used to infect subconfluent monolayers of Vero cells (Vero ATCC CCL-81 ${ }^{\mathrm{TM}}$, Manassas, VA, USA) or to stimulate NET production, as described later. Vero cells cultures re maintained at $37^{\circ} \mathrm{C}, 5 \% \mathrm{CO}_{2}$ in DMEM/F12 culture medium supplemented with $10 \%$ fetal calf serum and $1 \%$ penicillin-streptomycin antibiotic solution. Tachyzoites released from the supernatant of infected Vero cells a few days later were also used to stimulate NET production. They were harvested and isolated by differential centrifugation exactly as explained above for the peritoneum. To maintain their virulence, parasites are periodically passed in vivo.

Parasites of T. gondii ME49 strain are routinely maintained in C57BL/6 mice. Tissue cysts are obtained from the brains of mice inoculated intraperitoneally with 50 cysts/animal, as described elsewhere [38]. Briefly, cysts were ruptured with acid pepsin solution and free parasites were added to Vero cells cultures. Two weeks later, released tachyzoites from infected cells were collected from the 
supernatant as described above for the RH strain, washed, counted in a hemocytometer, and used to infect other Vero cultures or to stimulate NET production. To maintain their virulence, parasites are periodically passed in vivo.

Leishmania amazonensis promastigotes from MHOM/BR/77/LTB0016 strain were maintained at $26^{\circ} \mathrm{C}$ in Schneider's insect medium supplemented with $10 \%$ fetal calf serum. Stationary-phase promastigotes were obtained from 5-day-old cultures. Parasites were washed and counted in a hemocytometer.

\subsection{NET Induction/Inhibition Assay}

In order to induce NET production, neutrophils ( $10^{5}$ cells per well) were plated in 96-well plates and incubated with PMA, L. amazonensis promastigotes or T. gondii tachyzoites from either RH or ME49 strains (5:1 parasites/neutrophil ratio) for up to $180 \mathrm{~min}$ at $37{ }^{\circ} \mathrm{C}$ with $5 \% \mathrm{CO}_{2}$. Paraformaldehyde-fixed tachyzoites were used at the same parasite/neutrophil ratio as well. In some cases, neutrophils were treated for $30 \mathrm{~min}$ with one of the several pharmacological inhibitors listed above before adding T. gondii tachyzoites. Afterwards supernatants were collected, spun down for $5 \mathrm{~min}$, and stored at $-80{ }^{\circ} \mathrm{C}$ until use.

\subsection{Quantification of NET-Derived DNA}

Supernatants were distributed into 96-well opaque plates, and NET-derived DNA was quantified using the Quant-iT PicoGreen dsDNA Assay Kit according to manufacturer's instructions. Analysis was performed in a SpectraMax Paradigm microplate reader (Molecular Devices, Sunnyvale, CA, USA) using 485/538 nm excitation/emission wavelengths. Herring sperm DNA was used to make the standard concentration curve.

\subsection{Detection of Myeloperoxidase, Histone H1, and T. gondii}

Neutrophils $\left(2.5 \times 10^{5}\right.$ cells per well) were plated in 24-well plates with coverslips and incubated or not with $\mathrm{T}$. gondii tachyzoites from $\mathrm{RH}$ strain for $180 \mathrm{~min}$ at $37^{\circ} \mathrm{C}, 5 \% \mathrm{CO}_{2}$. Cultures were fixed with $4 \%$ paraformaldehyde for $30 \mathrm{~min}$ at room temperature and carefully washed with PBS. Coverslips were stained with anti-MPO and either anti-Histone $\mathrm{H} 1$ or anti-Toxoplasma gondii antibodies, followed by the secondary antibodies anti-mouse Alexa Fluor 594 and anti-rabbit Alexa Fluor 488. Slides were mounted with ProLong Diamond Antifade Mountant with DAPI and examined and photographed in a Zeiss Axio Imager.M1 microscope (Zeiss, Germany).

\subsection{Ultrastructural Visualization of T. gondii Entrapment in NET}

Neutrophils $\left(2.5 \times 10^{5}\right.$ cells per well $)$ were cultivated in 24 -well plates with coverslips and stimulated with T. gondii tachyzoites from $\mathrm{RH}$ strain for $180 \mathrm{~min}$ at $37{ }^{\circ} \mathrm{C}, 5 \% \mathrm{CO}_{2}$. Cells were fixed for $1 \mathrm{~h}$ at room temperature with 2.5\% glutaraldehyde in $0.1 \mathrm{M}$ sodium cacodylate buffer (pH 7.2) containing $3.5 \%$ sucrose and $2.5 \mathrm{mM} \mathrm{CaCl}_{2}$. After washing, cells were post-fixed with $1 \%$ osmium tetroxide and $0.8 \%$ potassium ferricyanide for $1 \mathrm{~h}$ at room temperature and dehydrated in crescent concentrations of ethanol. Following dehydration, the specimens were critical-point dried, coated with gold, and observed in a JEOL-JSM-6390LV scanning electron microscope (JEOL, Japan) from the Rudolf Barth Electron Microscopy Platform (Instituto Oswaldo Cruz, Fiocruz, Rio de Janeiro, RJ, Brazil).

\subsection{Production of NET-Enriched Supernatants}

Neutrophils $\left(6 \times 10^{5}\right.$ cells per well) were plated in 24 -well plates and incubated with T. gondii tachyzoites from $\mathrm{RH}$ strain (5:1 parasites/neutrophil ratio) for $180 \mathrm{~min}$ at $37^{\circ} \mathrm{C}, 5 \% \mathrm{CO}_{2}$. Afterwards supernatant was collected, spun down for $5 \mathrm{~min}$, and stored at $-80{ }^{\circ} \mathrm{C}$ until use. NET-DNA was quantified with the Quant-iT PicoGreen dsDNA Assay Kit as described before. NET-enriched supernatants were treated or not with DNase $(20 \mathrm{U} / \mathrm{mL})$ for $30 \mathrm{~min}$ and used in the parasite infectivity assay. 


\subsection{Parasite Infectivity Assay}

T. gondii tachyzoites from RH strain were incubated in NET-enriched supernatants $(\approx 1 \mu \mathrm{g} / \mathrm{mL}$ NET-DNA) for $180 \mathrm{~min}$ at $37^{\circ} \mathrm{C}, 5 \% \mathrm{CO}_{2}$. Supernatants were pretreated or not with $20 \mathrm{U} / \mathrm{mL}$ DNase for $30 \mathrm{~min}$ before adding parasites. Afterwards parasites were used to infect monolayers of Vero cells (1:1 parasite/Vero ratio) in coverslips for $180 \mathrm{~min}$. Cells were then washed to remove non-internalized parasites and kept at $37^{\circ} \mathrm{C}, 5 \% \mathrm{CO}_{2}$, for $21 \mathrm{~h}$. Coverslips were stained with Giemsa and observed in a Zeiss Axio Imager.A2 microscope. At least 200 cells were counted randomly in the central area of each slide. The infection index was calculated using the following formula:

$$
\text { Infection Index }=\frac{\% \text { Infected Cells } \times \text { Total Number of Intracellular Parasites }}{\text { Total Number of Cells }}
$$

\subsection{Neutrophil Viability Assay}

The cytotoxicity of the inhibitors to neutrophils was examined with PrestoBlue Cell Viability Reagent according to manufacturer's instructions. Briefly, neutrophils were incubated with inhibitors in the same conditions used for the NET induction assay, except that cells were not further stimulated. Cells were kept at $37^{\circ} \mathrm{C}, 5 \% \mathrm{CO}_{2}$, for $180 \mathrm{~min}$, and PrestoBlue was added $20 \mathrm{~min}$ before the end of the incubation time. Analysis was performed in a SpectraMax M2 microplate reader (Molecular Devices) using 560/590 nm excitation/emission wavelengths. Data is represented as percentage of control.

\subsection{Live Cell Imaging}

Neutrophils $\left(5 \times 10^{5}\right)$ were seeded in $35 \mathrm{~mm}$ CELLview plates (Greiner Bio-One, Americana, SP, Brazil) and allowed to adhere for $30 \mathrm{~min}$ at $37^{\circ} \mathrm{C}$. Afterwards, non-adherent cells were washed out and T. gondii tachyzoites from RH strain were added at a parasites:neutrophil ratio of 5:1 in $800 \mu \mathrm{L}$ of RPMI. Propidium iodide was added to the dish at a final concentration of $3 \mu \mathrm{g} / \mathrm{mL}$, in order to stain NET as well as dead neutrophils and parasites over time. Parasites were allowed to settle for $15 \mathrm{~min}$ before recording began. Spontaneous death of parasites in culture medium in the absence of neutrophils was also evaluated as a control condition. Time-lapse analysis was performed by sequential acquisition along several hours with a time interval of $30 \mathrm{~s}$, using a Zeiss Axio Observer Z1 microscope. Images were acquired by an HMR Axiocam monochrome camera operated by Axiovision software version 3.2 (Zeiss, Germany). The red signal from propidium iodide was acquired by Colibri illumination system using a $590 \mathrm{~nm}$ LED with Zeiss fluorescence filter 50. Temperature and focus were maintained along time-lapse analysis using a Temperature Control module and a Zeiss Definitive Focus device, respectively. Images were processed in ImageJ 1.52 (National Institutes of Health, Bethesda, MD, USA).

\subsection{Statistical Data Analysis}

The experiments were generally performed in duplicate and repeated two to six times, according to the number of blood samples (number of cats) available at the moment and the number of neutrophils that we were able to obtain from each blood sample. The number of cats for each day of experimentation ranged from one to six. Data are presented as the total number of cats tested for each experiment as mean \pm SD values. Comparisons between groups were done by paired $t$-test, after $\mathrm{D}^{\prime}$ Agostino-Pearson omnibus normality test, or repeated measures one-way ANOVA with Greenhouse-Geisser correction and Dunnett's multiple comparisons test, when appropriate. Differences of $p<0.05$ were considered to be significant. GraphPad Prism 7 software (GraphPad, San Diego, CA, USA) was used for all analyses.

\section{Results}

\subsection{Neutrophils from Cats Produce Extracellular Traps in Response to Classical Inducers}

We first investigated the ability of feline neutrophils to produce NET in response to either PMA, a well-known PKC activator and potent inducer of NET [39], or L. amazonensis, a protozoan parasite 
with a well-described capacity to induce NET both in vitro and in vivo [40-42], as our positive control conditions. As expected, treatment with PMA led to a two-fold increase in dsDNA release when compared to untreated cells (Supplementary Figure S1A). Stimulation of cells with L. amazonensis promastigotes induced a seven-fold increase in dsDNA production as compared to control cells (Supplementary Figure S1B), corroborating our previous findings [43,44]. These results confirm that neutrophils from cats are competent in producing NET triggered by various stimuli as part of its repertoire of immune responses.

\subsection{Cat Neutrophils Produce Extracellular Traps in Response to Toxoplasma gondii}

We next examined whether neutrophils from cats produce NET as a strategy to combat infection by $T$. gondii. NET production was accompanied for up to $180 \mathrm{~min}$ after incubating neutrophils with tachyzoites from two clonal strains of the parasite, RH (type I, virulent strain) or ME49 (type II, cystogenic strain). T. gondii induced dsDNA release by neutrophils in a strain- and time-dependent manner, beginning as early as $15 \mathrm{~min}$ after incubation with parasites (Figure 1). Interestingly, production of NET in response to RH strain was more pronounced than to ME49 strain at later time points (Figure 1A,E; 4.0- and 4.9-fold change for RH and 2.9- and 2.7-fold change for ME49 at 60 and $180 \mathrm{~min}$, respectively, when compared to control). This assay was performed with neutrophils from at least 10 different cats, and although the extent of the response varies from one donor to the other, the response pattern is the same for all donors (Figure 1B,F). Paraformaldehyde fixed parasites induced far less NET than live parasites (Figure 1C,G), suggesting that NET production may have the contribution of factors released by $T$. gondii. We cannot rule out the possibility that the fixation process itself could alter the conformation of the parasite's surface molecules [45], thereby affecting their recognition by the receptors involved in NET release.
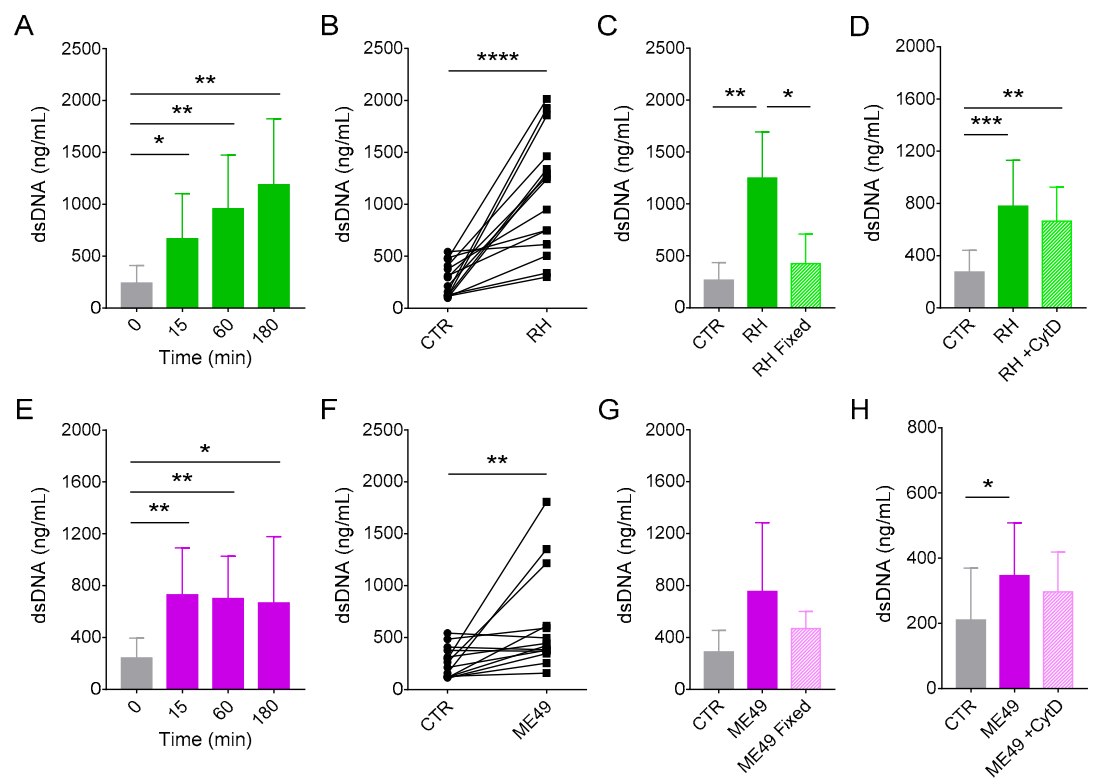

Figure 1. Toxoplasma gondii induce neutrophil extracellular trap (NET) release from cat neutrophils. Neutrophils from several donors were incubated for the indicated time intervals in the absence (CTR) or presence of tachyzoites from (A-D) RH or (E-H) ME49 strains (5:1 parasites:neutrophil ratio). Supernatants were collected and released dsDNA was quantified with PicoGreen Kit. (A,E) Release of NET from feline neutrophils is strain- and time-dependent $(n=10-12)$. (B,F) Interdonor variations in dsDNA release after 180 min incubation with parasites $(n=14-15)$. (C,G) NET induction by paraformaldehyde-fixed or live parasites after 180 min incubation $(n=8-9)$. (D,H) Formation of NET does not require invasion of neutrophils by the parasites. Cat neutrophils were pretreated or not with cytochalasin D (CytD; $10 \mu \mathrm{g} / \mathrm{mL})$ for $30 \mathrm{~min}$ and then stimulated with T. gondii tachyzoites $(n=5-12)$. All results are shown as mean (SD). ${ }^{*} p<0.05$; ${ }^{* *} p<0.01$; ${ }^{* * *} p<0.001$; ${ }^{* * * *} p<0.0001$. 
In order to determine if NET production in response to live parasites would be triggered during invasion of neutrophils by T. gondii, we treated neutrophils for $30 \mathrm{~min}$ with the actin polymerization inhibitor cytochalasin D before adding the parasites. Pretreatment of cells with CytD did not affect dsDNA release by cat neutrophils (Figure 1D,H), indicating that the invasion of cells is dispensable for NET production in response to T. gondii.

\subsection{NET from Cats Entrap Toxoplasma gondii Tachyzoites}

In order to investigate the components associated with feline NET and the capacity of those NET to entrap parasites, we performed a microscopic analysis of the parasite-NET interaction. After $180 \mathrm{~min}$ interaction of T. gondii with neutrophils, cells were fixed, stained for myeloperoxidase, histone H1 or the parasite and DNA, and examined in a fluorescence microscope. We found that NET released in response to T. gondii tachyzoites contains all the classical NET signatures (Figure 2A), and that many parasites are entangled in DNA-MPO structures (Figure 2B).

A
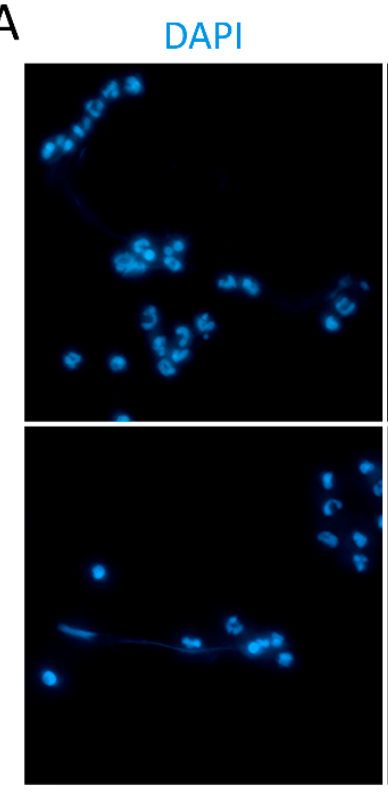

B

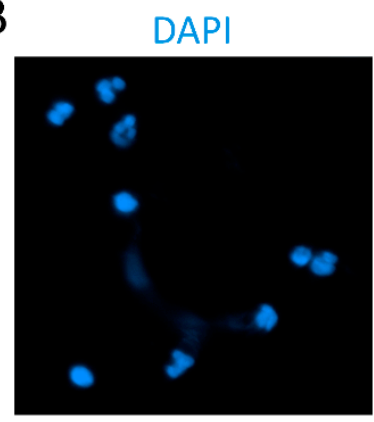

MPO

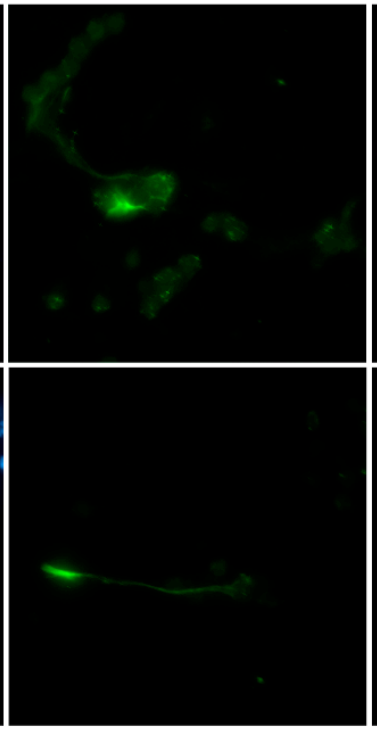

$\mathrm{MPO}$

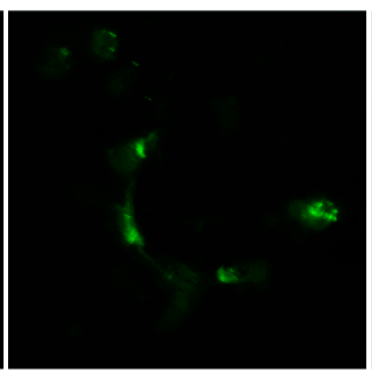

$\mathrm{H} 1$

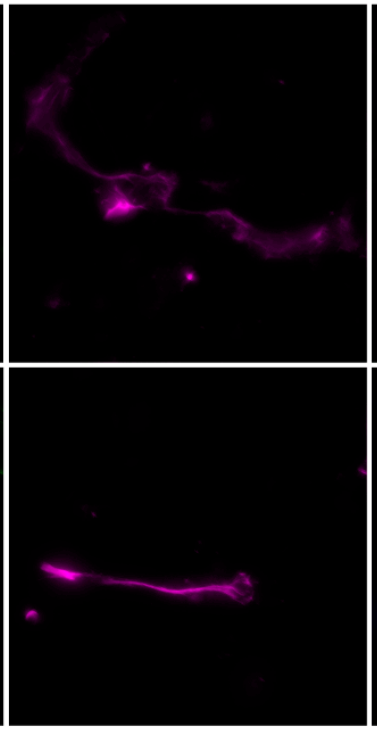

DAPI / MPO / Tg

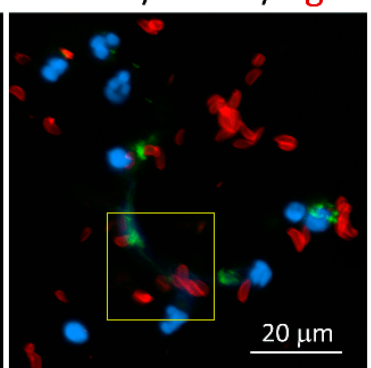

DAPI / MPO / H1

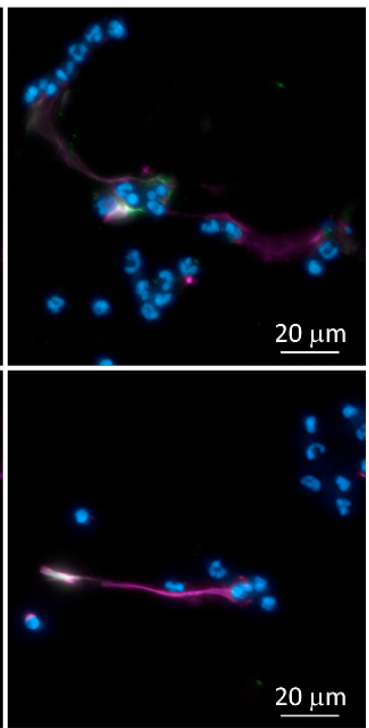

Inset

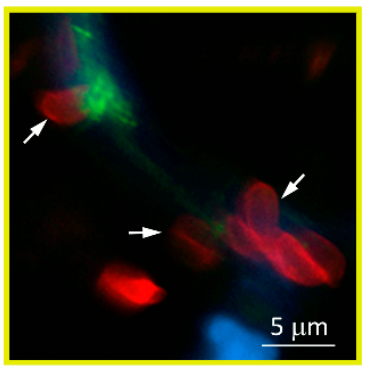

Figure 2. NET formation induced by Toxoplasma gondii tachyzoites. Neutrophils were incubated for 180 min with RH strain tachyzoites (5:1 parasites:neutrophil ratio), fixed and stained for myeloperoxidase (MPO) and histone H1 (A) or T. gondii (B). Neutrophils DNA was counterstained with DAPI. Inset shows a region containing several parasites entrapped in DNA-MPO rich structures (arrows). $\mathrm{Tg}=\mathrm{T}$. gondii.

We further analyzed the ultrastructural aspects of parasite-NET interactions. Neutrophils were incubated with T. gondii tachyzoites for $180 \mathrm{~min}$, fixed, processed as described in methods, and observed in a scanning electron microscope. Three representative fields were photographed at different magnifications, showing either strands or networks of extracellular DNA in close association with 
T. gondii tachyzoites (Figure 3). In some cases, parasites can be seen completely entrapped in the network of NET produced by cat neutrophils (Figure 3G,J,K).
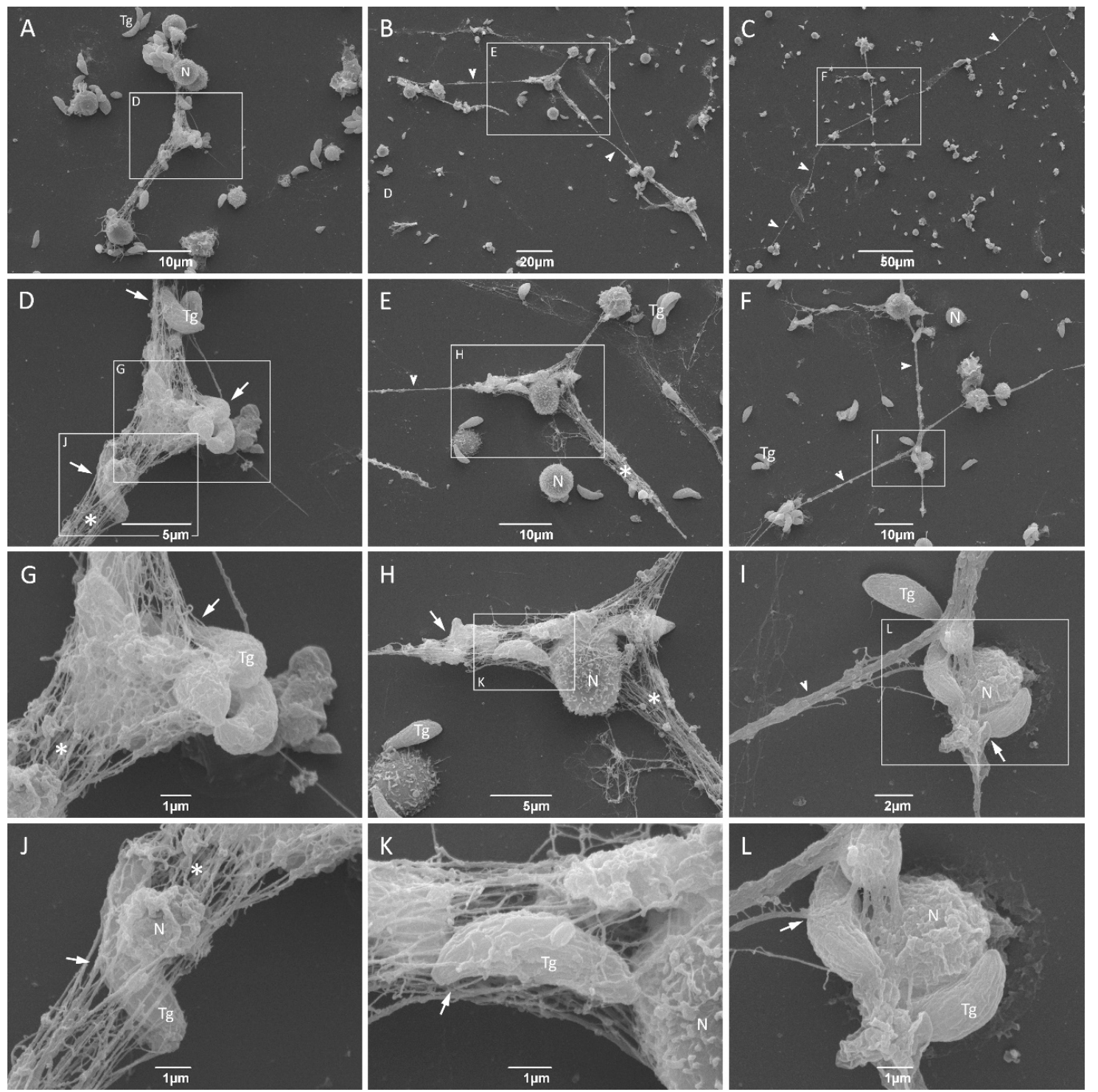

Figure 3. Ultrastructural aspects of T. gondii and cat NET interactions. Neutrophils were incubated for 180 min with tachyzoites from RH strain (5:1 parasites:neutrophil ratio), fixed and processed for scanning electron microscopy (A-L). Strands (arrowheads) or networks (asterisks) of NET can be seen entrapping tachyzoites of $T$. gondii (arrows). Selected areas indicated by rectangles are zoomed in the picture bellow. $\mathrm{Tg}=T$. gondii; $\mathrm{N}=$ neutrophil.

\subsection{Release of dsDNA from Cat Neutrophils in Response to T. gondii Depends on Elastase, Calcium, and PI3KX}

To further elucidate the mechanisms involved in NET release by cat neutrophils in response to T. gondii tachyzoites, we pretreated neutrophils with one of several inhibitors before adding parasites. We first assessed the role of elastase, myeloperoxidase, and PAD4 on dsDNA release after $180 \mathrm{~min}$. Administration of elastase inhibitor decreased NET-derived DNA production by cat neutrophil by 27\% (Figure 4A). MPO or PAD inhibition did not affect dsDNA release by neutrophils stimulated with T. gondii (Supplementary Figure S2A,B). Importantly, the inhibitors herein used were not toxic to neutrophils (Supplementary Figure S3). 

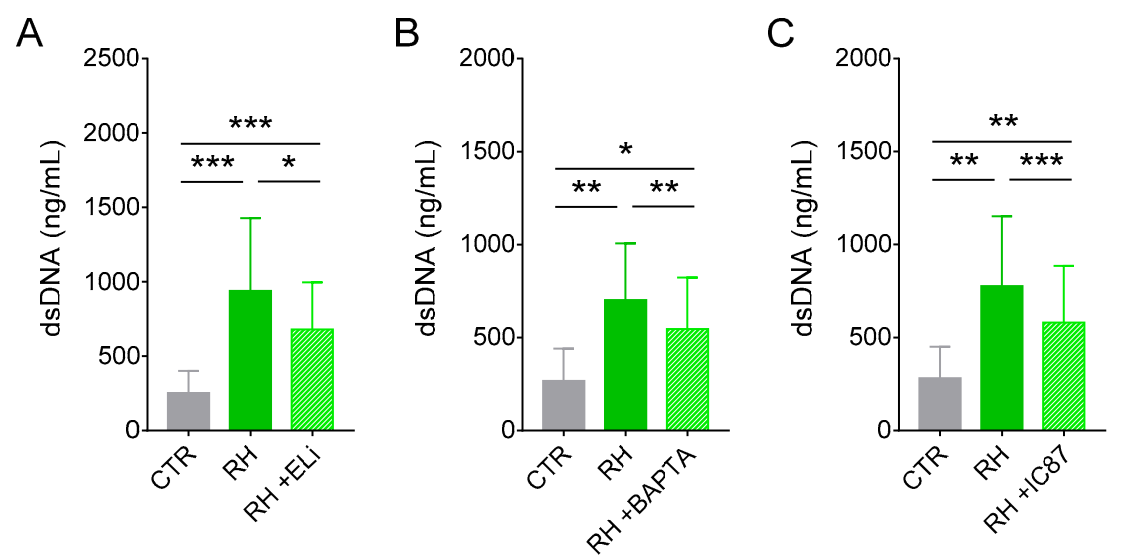

Figure 4. Classical NET-derived DNA release in response to T. gondii involves elastase, intracellular calcium, and PI3K $\delta$. Neutrophils were pretreated or not with (A) the elastase inhibitor MeOSuc-AAPV-CMK (Eli; $10 \mu \mathrm{g} / \mathrm{mL}$ ), (B) the intracellular calcium chelator BAPTA/AM (BAPTA; $10 \mu \mathrm{M}$ ), or (C) the PI3K $\delta$ selective inhibitor IC87114 (IC87; $1 \mu \mathrm{M})$ for $30 \mathrm{~min}$ and then stimulated for $180 \mathrm{~min}$ with RH tachyzoites (5:1 parasites:neutrophil ratio). Supernatants were collected and released dsDNA was quantified with PicoGreen Kit $(n=9-13)$. All results are shown as mean (SD). ${ }^{*} p<0.05 ;{ }^{* *} p<0.01 ;{ }^{* * *} p<0.001$.

Next, we investigated the role of calcium, PI3K, and MEK signaling pathways in feline NET induced by T. gondii. Pretreatment of neutrophils with a calcium chelator led to a $22 \%$ inhibition in dsDNA release by cat neutrophils (Figure 4B). Administration of a PI3K $\delta$ selective inhibitor decreased by $26 \%$ the release of NET-derived DNA triggered by T. gondii (Figure $4 \mathrm{C}$ ). Interestingly, treatment of feline neutrophils with a PI3K $\gamma$ selective inhibitor had no effect on dsDNA release in response to tachyzoites (Supplementary Figure S2C). Inhibition of MEK had no effect on dsDNA release by cat neutrophils in the presence of T. gondii (Supplementary Figure S2D). Of note, the calcium chelator and the inhibitors for PI3K $\delta, \operatorname{PI} 3 \mathrm{~K} \gamma$, and MEK presented no toxicity to neutrophils after $180 \mathrm{~min}$ (Supplementary Figure S3).

\subsection{NET from Cats Kill Toxoplasma gondii Tachyzoites}

To verify the capacity of feline NET to affect infectivity of $T$. gondii, we incubated parasites for $180 \mathrm{~min}$ in NET-enriched supernatants pretreated or not with DNase and examined the ability of the tachyzoites to infect Vero cells. We found an infection index $47 \%$ higher when Vero cells were incubated with parasites treated with NET-enriched supernatants in the presence of DNase than with parasites treated in the absence of DNase (Figure 5), suggesting that NET directly inhibit T. gondii infectivity.

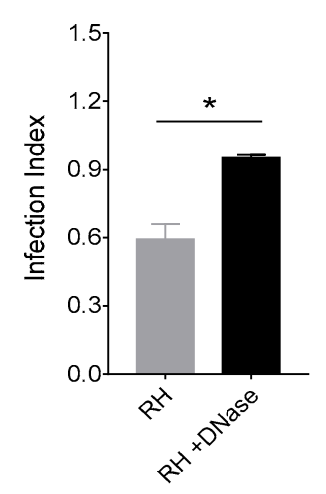

Figure 5. NET decreases T. gondii infectivity to host cells. Tachyzoites of RH strain were incubated in NET-enriched supernatants pretreated or not with DNase for $30 \mathrm{~min}$. Parasites were further used to infect Vero cells (1:1 parasite:Vero ratio) for $180 \mathrm{~min}$, and the infection index was determined after $21 \mathrm{~h}$ culture. Data from two independent experiments are shown as mean (SD). ${ }^{*} p<0.05$. 
Finally, we asked whether inhibition of T. gondii infectivity could be due to parasite killing by NET. We performed a time-lapse analysis of neutrophils incubated with T. gondii, and found that neutrophils can release NET from as early as $15 \mathrm{~min}$ to up to $180 \mathrm{~min}$ of interaction with parasites (Figure 6 and Supplementary Video S1 depict the release of NET after 80 min interaction with the parasite). As expected, parasites entrapped in NET died over time, as seen by propidium iodide incorporation (Figure 7), suggesting that loss of host cells infectivity is caused by a loss of T. gondii tachyzoites viability. Noteworthy, parasites incubated in culture medium in the absence of neutrophils remained alive for up to $5 \mathrm{~h}$ (Supplementary Figure S4), confirming that the death of tachyzoites was caused by NET.

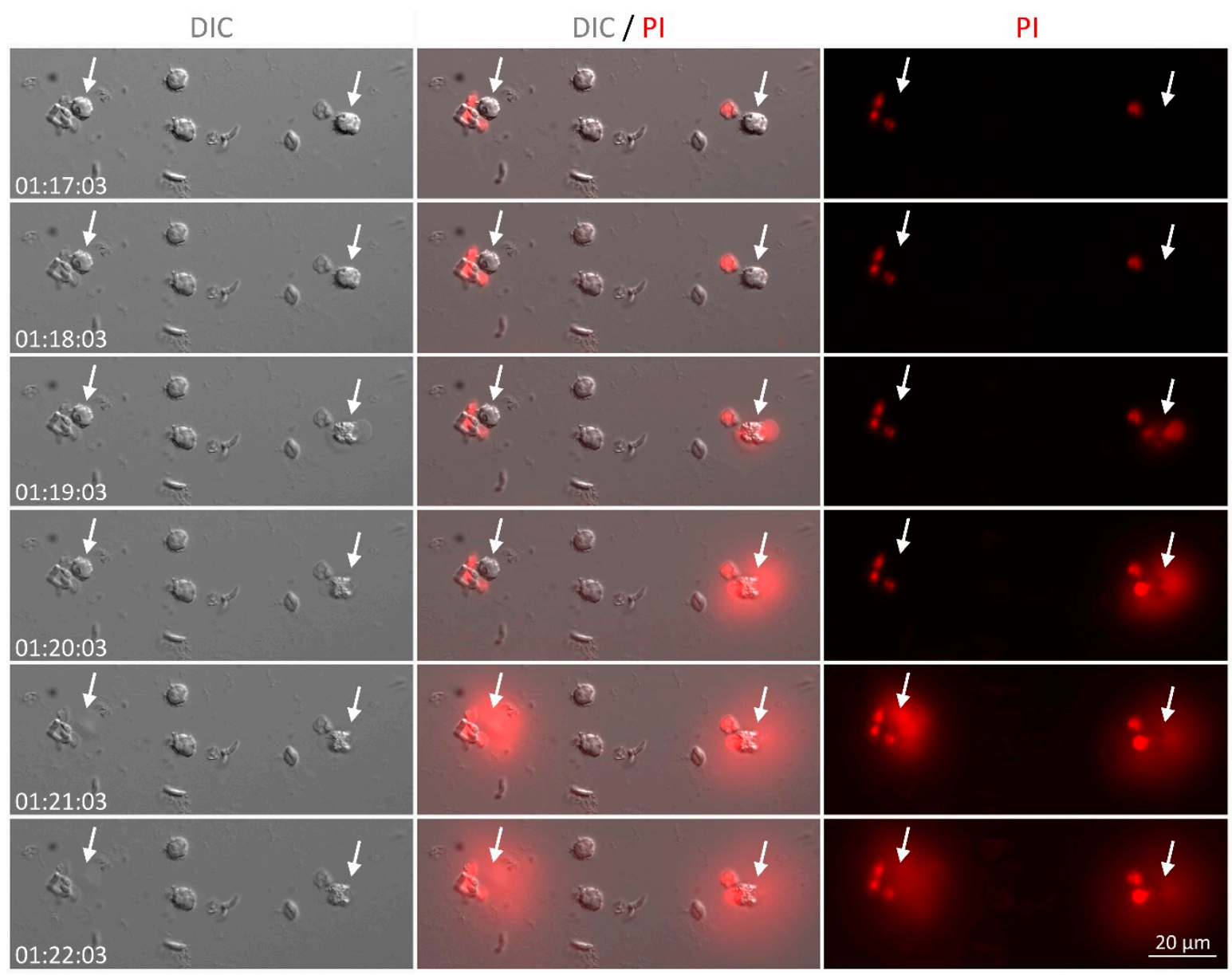

Figure 6. Time lapse recording of NET release by cat neutrophils in response to T. gondii. Neutrophils were stimulated with RH tachyzoites (5:1 parasites:neutrophil ratio) in the presence of propidium iodide (PI). Arrows point to neutrophils releasing NET after about $80 \mathrm{~min}$ of interaction with parasites. DIC $=$ differential interference contrast. 


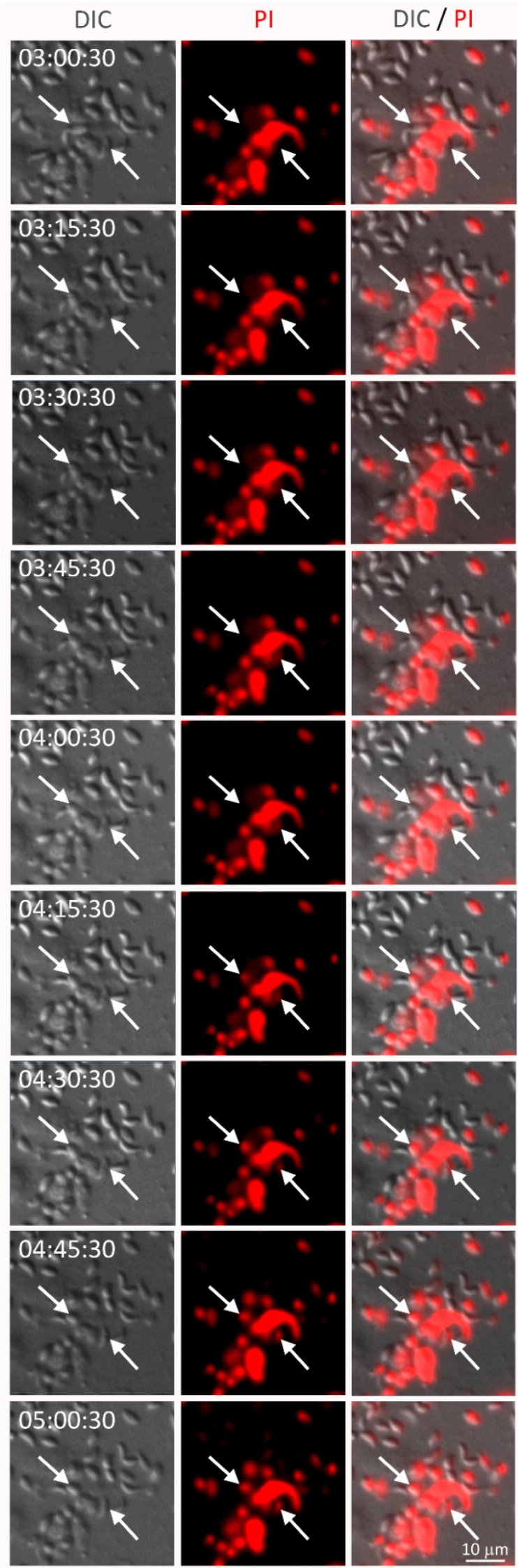

Figure 7. Tachyzoites of T. gondii die in contact with feline NET. Neutrophils were stimulated with RH tachyzoites (5:1 parasites:neutrophil ratio) in the presence of propidium iodide (PI) and images were recorded during the time. Arrows point to two parasites dying after contact with NET. DIC = differential interference contrast. 


\section{Discussion}

Although several studies have called attention to the importance of neutrophils in the infection and spread by Toxoplasma gondii in mice $[16,29,46-48]$, the role of neutrophils in feline toxoplasmosis remains poorly explored. In general, gaining knowledge in the field of parasite-neutrophil interaction will help to elucidate the mechanisms involved in the evasion of the parasite from the immune system and in the establishment of the disease. Here, we elucidated part of the molecular mechanisms involved in NET production induced by T. gondii in cat neutrophils, evidencing the participation of neutrophil elastase, intracellular calcium, and PI3K $\delta$ in the process.

Neutrophil extracellular trap production in response to T. gondii was first described by Abi Abdallah and colleagues, showing that neutrophils from humans and mice release NET induced by tachyzoites through a MAPK-partially dependent pathway, and that NET reduce parasite viability [29]. A few years later, production of NET in response to T. gondii infection was shown for other intermediate hosts. Neutrophils from dog [35], sheep and cattle [31], donkey [34], harbour seal [30], and dolphin [33] all release NET induced by this parasite. Moreover, Lacerda and colleagues recently showed that neutrophils from cats also produce NET in response to T. gondii [36], although without exploring its mechanism or NET toxicity to the parasite. Here we show that cat neutrophils produce classical NET in response to tachyzoites of the virulent strain $\mathrm{RH}$, corroborating previous findings [36]. Furthermore, we show that the cystogenic strain ME49 also induces NET release, and that production of NET by cat neutrophils in response to both virulent or cystogenic strains occurs either in a classical way, after a few hours, or in a rapid way, within the first $15 \mathrm{~min}$ of interaction with parasites. Early NET release has been previously shown for neutrophils from intermediate hosts in response to RH strain $[30,31,34,35]$ and from bovine neutrophils stimulated with a related apicomplexan parasite, Besnoitia besnoiti [49]. Zhou and colleagues present evidence that bovine neutrophils produce NET within $\approx 30$ min of interaction with $B$. besnoiti bradyzoites, and that the overall phenotype and crawling activities of neutrophils seem not to be affected by this event, suggesting that the rapid NET release is vital [49]. Those results corroborate previous findings with unrelated protozoan [23] and other microorganisms [22]. Whether neutrophils from cats remain alive after rapid NET release in response to $T$. gondii deserves further investigations.

We found that production of cat NET in response to the virulent RH strain was more pronounced than that triggered by the cystogenic ME49 strain over time. These differences might somehow reflect the differences in host immune response induced by those strains [50]. Moreover, it seems that the parasites affect NET production by releasing soluble factors, and not only by direct contact, since paraformaldehyde fixed tachyzoites induced much less NET than live ones. In this line of reasoning, Abi Abdallah and colleagues showed that internalization of tachyzoites by human neutrophils is not necessary for NET production [29]. Here we corroborate those findings and show that pretreatment of cat neutrophils with cytochalasin —a drug that inhibits actin polymerization, thereby preventing phagocytosis-does not significantly impact NET production. However, we cannot rule out the possibility that the phagocytosis-independent active internalization of parasites, especially in the virulent RH strain [51,52], can play a role in the process of NET production. In addition, the fixation of tachyzoites with paraformaldehyde could alter the conformation of molecules [45] on the parasite's cell surface, which could somehow be involved in neutrophil receptor recognition during NET release. Additional studies are necessary to elucidate these questions.

Further, we examined the components and ultrastructural aspects of cat NET and its capacity to ensnare tachyzoites of the virulent RH strain of T. gondii. We identified histone $\mathrm{H} 1$ as well as myeloperoxidase associated with the released DNA. Moreover, several tachyzoites were seen associated with cat NET. By scanning electron microscopy, we observed strands as well as networks of chromatin fibers entangling parasites. Previous studies have categorized NET according to different morphological structures: diffuse NET (diff NET), consisting of extracellular decondensed chromatin presented in a circular form and close to the cell body; spread NET (sprNET), corresponding to elongated web-like structures composed of thin chromatin fibers; aggregated NET ( $a g g \mathrm{NET})$, characterized by large clusters 
of NET aggregating many neutrophils with a massive appearance [53-55]. We show here that the NET produced by cat neutrophils after $180 \mathrm{~min}$ of interaction with RH tachyzoites are very similar to sprNET. Imlau and colleagues show that neutrophils isolated from dolphins produce all three types of NET, with a predominance of sprNET and aggNET [32]. Here, we did not find large clusters of NET aggregating neutrophils, but eventually small clusters could be seen (Supplementary Figure S5), corroborating previous findings and suggesting a conserved mechanism of NET release in response to T. gondii.

NET's antimicrobial activity can lead to death of various groups of pathogens, including bacteria, fungi, and protozoa. This is accomplished by the presence in NET of a plethora of proteases, antimicrobial enzymes, histones, and DNA, all of which contribute toward direct antimicrobial effects [56]. Here we investigated the ability of cat NET to inhibit infectivity and kill ensnared T. gondii. We show that treatment of NET-enriched supernatants with DNase increases the infectivity of tachyzoites to epithelial cells, and that entangled parasites are killed by NET, corroborating previous findings with mice neutrophils [29]. Interestingly, our live cell imaging analysis reveals that not all the parasites associated with NET died over a long time frame of recording. There is growing evidence that some microorganisms developed the ability to escape NET by degrading NET structure, inhibiting NET release, or resisting NET killing [57]. Degradation of NET are usually achieved by nucleases produced by pathogens, and we have previously shown that the expression of the enzyme $3^{\prime}$-nucleotidase/nuclease ( $\left.3^{\prime} \mathrm{NT} / \mathrm{NU}\right)$ by Leishmania parasites contributes to their escape from NET killing [58]. On the other hand, nuclease production can be associated with the degree of virulence of some parasites [57,59]. Therefore, it is tempting to speculate that the virulent RH tachyzoites we used in our assays are producing nucleases or other factors which could degrade NET and enable the survival and/or escape of at least part of the parasite population. Corroborating this hypothesis, Wei and colleagues recently showed that $T$. gondii tachyzoites from the same strain can degrade NET induced by zimosan [35]. Additional investigations are needed to elucidate the molecular factors involved there.

The mechanisms involved in the release of NET have been focus of intensive investigation in recent years. Although not fully understood, the molecular mechanisms of classical NET release involves different molecules and signaling pathways, including the activation of the Raf-MEK-ERK pathway and the generation of ROS by NADPH oxidase [53,60], the translocation of neutrophil elastase to the nucleus, and the association of MPO to the DNA, leading to chromatin decondensation [61] and the citrullination of histones by the nuclear enzyme peptidyl arginine deiminase-4 (PAD4), mediated by intracellular $\mathrm{Ca}^{2+}$ influx and ROS, also leading to decondensation of chromatin $[62,63]$. Reichel and colleagues showed that inhibition of neutrophil elastase or MPO completely abrogated dsDNA release by neutrophils from harbour seal stimulated with T. gondii [30]. However, it is not clear whether NET production by cat neutrophils depends on MPO or elastase. We therefore examined the role of these molecules and found that inhibition of elastase but not of MPO significantly affected dsDNA release, indicating that elastase is more important than MPO in our model.

In a recent report, Wei and colleagues showed that treatment of dog neutrophils with the NADPH oxidase inhibitor diphenylene iodonium (DPI) prevented DNA release in response to T. gondii [35]. Similar results were obtained with donkey neutrophils [34]. In another study, Reichel and others disclosed that inhibition of NADPH oxidase with the same inhibitor prevented NET release by neutrophils from harbour seal stimulated with T. gondii. Since the mechanism of ROS production is dependent on $\mathrm{Ca}^{2+}$ and the store-operated $\mathrm{Ca}^{2+}$ entry (SOCE) plays a fundamental role in this process [64,65], the authors investigated the involvement of $\mathrm{Ca}^{2+}$ and showed that the inhibition of the SOCE pathway significantly reduced dsDNA release, suggesting the participation of $\mathrm{Ca}^{2+} / \mathrm{SOCE}$ in the process of NET release in harbour seal [30]. Recently, cat neutrophils have been shown to produce ROS after stimulation with T. gondii [36]. However, if the release of NET by cat neutrophils depends on the production of ROS is something that deserves further investigation. Unfortunately, we could not provide additional information about the direct role of NADPH oxidase and ROS production in 
the process of NET release by cat neutrophils, since treatment of our cells with DPI led to massive neutrophils death (data not shown). On the other hand, we show the involvement of $\mathrm{Ca}^{2+}$ in cat NET production after treating cells with the intracellular $\mathrm{Ca}^{2+}$ chelator BAPTA/AM, corroborating previous findings [30]. Interestingly, treatment with the PAD inhibitor chloroamidine did not prevent NET release by cat neutrophils, suggesting the existence of a PAD-independent mechanism of NET release that might be influenced by intracellular $\mathrm{Ca}^{2+}$ concentration.

We have shown previously that production of NET induced by Leishmania amazonensis is partially dependent on PI3K signaling pathway, either through PI3K $\delta$ and PI3K $\gamma$ isoforms [44]. These isoforms are commonly expressed in leukocytes, and together they regulate several functions of the immune system [66]. Whereas PI3K $\gamma$ regulate ROS generation, PI3K $\delta$ is dispensable for this process, although it is important for the amplification of a second wave of ROS production dependent on the first wave initiated by PI3K $\gamma$ [67]. Here, we showed that the blockage of PI3K $\delta$ with a selective inhibitor decreased NET release in response to T. gondii by cat neutrophils. Surprisingly, administration of a PI3K $\gamma$ selective inhibitor had no effect on NET production in our model, indicating that generation of ROS might be secondary in NET release by cat neutrophils. Accordingly, MEK1/2 inhibition also had no effect on NET release by cat neutrophils in the presence of T. gondii, unlike what was found for human neutrophils, where NET production involves activation of ERK1/2 signaling pathway and where blockage of MEK1/2 partially prevents the release of NET [29]. These discrepancies may reflect the existence of different signaling pathways for NET release between different species in response to the T. gondii.

Much progress has been made in recent years with regard to the need of different molecular pathways to induce NET depending on the stimulus, and despite being important for the classical NET release for some stimuli, NAPDH oxidase, ROS, MPO, and neutrophil elastase are not necessary to induce NET by other stimuli $[39,68]$. Therefore, we speculate here that although production of NET is a conserved mechanism between different species, neutrophils from different organisms may use different signaling pathways to induce NET to the same stimulus. Further comparative studies are needed to test this hypothesis.

\section{Conclusions}

We show for the first time that neutrophils from cats release both classical and rapid/early NET in response to either virulent or cystogenic strains of T. gondii, and that the parasites are entrapped and killed by NET. The mechanisms of classical release of cat NET to T. gondii tachyzoites involve the participation of neutrophil elastase, intracellular calcium, and PI3K $\delta$ signaling pathways.

Supplementary Materials: The following are available online at http://www.mdpi.com/2076-2607/8/11/1628/s1, Figure S1: Neutrophils from cats produce NET in response to PMA and Leishmania amazonensis, Figure S2: Release of classical NET-derived DNA in response to T. gondii is independent of MPO, PAD, PI3K $\gamma$, and MEK, Figure S3: Neutrophil viability after treatment with inhibitors, Figure S4: Spontaneous death of Toxoplasma gondii in culture medium, Figure S5: NET formation induced by Toxoplasma gondii tachyzoites, Video S1: Time lapse video showing the release of NET by cat neutrophils in response to T. gondii., Video S2: Tachyzoites of T. gondii dying in contact with cat NET.

Author Contributions: Conceptualization, R.M.M.; Formal analysis, R.M.M.; Funding acquisition, R.M.M.; Investigation, I.S.M., M.V.A.L., J.S.S., N.C.R., F.A.L. and R.M.M.; Methodology, I.S.M., M.V.A.L. and R.M.M.; Project administration, R.M.M.; Resources, P.N.C., H.S.B., F.A.L., E.M.S. and R.M.M.; Supervision, R.M.M.; Visualization, J.S.S. and R.M.M.; Writing-original draft, I.S.M., M.V.A.L. and R.M.M.; Writing-review and editing, I.S.M., M.V.A.L., J.S.S., N.C.R., P.N.C., H.S.B., F.A.L., E.M.S. and R.M.M. All authors have read and agreed to the published version of the manuscript.

Funding: This research was funded by Conselho Nacional de Desenvolvimento Científico e Tecnológico (CNPq, Chamada Universal 432255/2016-8), Fundação Carlos Chagas Filho de Amparo à Pesquisa do Estado do Rio de Janeiro (FAPERJ, Bolsas E-26/260.A58/2018 and E-26/260.048/2018, Redes de Pesquisa em Saúde E-26/211.570/2019), Coordenação de Aperfeiçoamento de Pessoal de Nível Superior (CAPES, Finance Code 001), and Fundação Oswaldo Cruz (Fiocruz). 
Acknowledgments: The authors thank Sandra Maria de Oliveira Souza (Instituto Oswaldo Cruz, Fiocruz) for her technical assistance and Veronica Schmitz Pereira (Instituto Oswaldo Cruz, Fiocruz) and Rodrigo da Cunha Bisaggio (Instituto Federal de Educação, Ciência e Tecnologia do Rio de Janeiro, IFRJ) for the critical discussions about the data of this manuscript.

Conflicts of Interest: The authors declare no conflict of interest. The funders had no role in the design of the study; in the collection, analyses, or interpretation of data; in the writing of the manuscript, or in the decision to publish the results.

\section{References}

1. Tenter, A.M.; Heckeroth, A.R.; Weiss, L.M. Toxoplasma gondii: From animals to humans. Int. J. Parasitol. 2000, 30, 1217-1258. [CrossRef]

2. Dubey, J.P. History of the discovery of the life cycle of Toxoplasma gondii. Int. J. Parasitol. 2009, 39, 877-882. [CrossRef] [PubMed]

3. Pappas, G.; Roussos, N.; Falagas, M.E. Toxoplasmosis snapshots: Global status of Toxoplasma gondii seroprevalence and implications for pregnancy and congenital toxoplasmosis. Int. J. Parasitol. 2009, 39, 1385-1394. [CrossRef] [PubMed]

4. Holland, G.N. Ocular toxoplasmosis: A global reassessment. Part I: Epidemiology and course of disease. Am. J. Ophthalmol. 2003, 136, 973-988. [CrossRef] [PubMed]

5. Dupont, C.D.; Christian, D.A.; Hunter, C.A. Immune response and immunopathology during toxoplasmosis. Semin. Immunopathol. 2012, 34, 793-813. [CrossRef] [PubMed]

6. Ferguson, D.J.P.; Bowker, C.; Jeffery, K.J.M.; Chamberlain, P.; Squier, W. Congenital toxoplasmosis: Continued parasite proliferation in the fetal brain despite maternal immunological control in other tissues. Clin. Infect. Dis. 2013, 56, 204-208. [CrossRef] [PubMed]

7. Dubey, J.P.; Swan, G.V.; Frenkel, J.K. A simplified method for isolation of Toxoplasma gondii from the feces of cats. J. Parasitol. 1972, 58, 1005-1006. [CrossRef]

8. Dubey, J.P. Toxoplasmosis-A waterborne zoonosis. Vet. Parasitol. 2004, 126, 57-72. [CrossRef]

9. Osbaldiston, G.W. Haematological values in healthy cats. Br. Vet. J. 1978, 134, 524-536. [CrossRef]

10. Van Gisbergen, K.P.J.M.; Geijtenbeek, T.B.H.; Van Kooyk, Y. Close encounters of neutrophils and DCs. Trends Immunol. 2005, 26, 626-631. [CrossRef]

11. Jaillon, S.; Galdiero, M.R.; Del Prete, D.; Cassatella, M.A.; Garlanda, C.; Mantovani, A. Neutrophils in innate and adaptive immunity. Semin. Immunopathol. 2013, 35, 377-394. [CrossRef]

12. Nauseef, W.M.; Borregaard, N. Neutrophils at work. Nat. Immunol. 2014, 15, 602-611. [CrossRef] [PubMed]

13. Liew, P.X.; Kubes, P. The Neutrophil's Role During Health and Disease. Physiol. Rev. 2019, 99, $1223-1248$. [CrossRef]

14. Bliss, S.K.; Butcher, B.A.; Denkers, E.Y. Rapid recruitment of neutrophils containing prestored IL-12 during microbial infection. J. Immunol. 2000, 165, 4515-4521. [CrossRef] [PubMed]

15. Norose, K.; Naoi, K.; Fang, H.; Yano, A. In vivo study of toxoplasmic parasitemia using interferon-gammadeficient mice: Absolute cell number of leukocytes, parasite load and cell susceptibility. Parasitol. Int. 2008, 57, 447-453. [CrossRef]

16. Coombes, J.L.; Charsar, B.A.; Han, S.J.; Halkias, J.; Chan, S.W.; Koshy, A.A.; Striepen, B.; Robey, E.A. Motile invaded neutrophils in the small intestine of Toxoplasma gondii-infected mice reveal a potential mechanism for parasite spread. Proc. Natl. Acad. Sci. USA 2013, 110, E1913-E1922. [CrossRef]

17. Faurschou, M.; Sørensen, O.E.; Johnsen, A.H.; Askaa, J.; Borregaard, N. Defensin-rich granules of human neutrophils: Characterization of secretory properties. Biochim. Biophys. Acta 2002, 1591, 29-35. [CrossRef]

18. Faurschou, M.; Borregaard, N. Neutrophil granules and secretory vesicles in inflammation. Microbes Infect. 2003, 5, 1317-1327. [CrossRef]

19. Brinkmann, V.; Reichard, U.; Goosmann, C.; Fauler, B.; Uhlemann, Y.; Weiss, D.S.; Weinrauch, Y.; Zychlinsky, A. Neutrophil extracellular traps kill bacteria. Science 2004, 303, 1532-1535. [CrossRef]

20. Kolaczkowska, E.; Kubes, P. Neutrophil recruitment and function in health and inflammation. Nat. Rev. Immunol. 2013, 13, 159-175. [CrossRef]

21. Pilsczek, F.H.; Salina, D.; Poon, K.K.H.; Fahey, C.; Yipp, B.G.; Sibley, C.D.; Robbins, S.M.; Green, F.H.Y.; Surette, M.G.; Sugai, M.; et al. A novel mechanism of rapid nuclear neutrophil extracellular trap formation in response to Staphylococcus aureus. J. Immunol. 2010, 185, 7413-7425. [CrossRef] [PubMed] 
22. Yipp, B.G.; Kubes, P. NETosis: How vital is it? Blood 2013, 122, 2784-2794. [CrossRef] [PubMed]

23. Rochael, N.C.; Guimarães-Costa, A.B.; Nascimento, M.T.C.; DeSouza-Vieira, T.S.; Oliveira, M.P.; Garcia e Souza, L.F.; Oliveira, M.F.; Saraiva, E.M. Classical ROS-dependent and early/rapid ROS-independent release of Neutrophil Extracellular Traps triggered by Leishmania parasites. Sci. Rep. 2015, 5, 18302. [CrossRef] [PubMed]

24. Schönrich, G.; Raftery, M.J. Neutrophil Extracellular Traps Go Viral. Front. Immunol. 2016, 7, 366. [CrossRef]

25. Silva, L.M.R.; Muñoz-Caro, T.; Burgos, R.A.; Hidalgo, M.A.; Taubert, A.; Hermosilla, C. Far beyond Phagocytosis: Phagocyte-Derived Extracellular Traps Act Efficiently against Protozoan Parasites In Vitro and In Vivo. Mediat. Inflamm. 2016, 2016, 5898074. [CrossRef]

26. Hoppenbrouwers, T.; Autar, A.S.A.; Sultan, A.R.; Abraham, T.E.; Van Cappellen, W.A.; Houtsmuller, A.B.; Van Wamel, W.J.B.; Van Beusekom, H.M.M.; Van Neck, J.W.; De Maat, M.P.M. In vitro induction of NETosis: Comprehensive live imaging comparison and systematic review. PLoS ONE 2017, 12, e0176472. [CrossRef]

27. Díaz-Godínez, C.; Carrero, J.C. The state of art of neutrophil extracellular traps in protozoan and helminthic infections. Biosci. Rep. 2019, 39, BSR20180916. [CrossRef]

28. Urban, C.F.; Nett, J.E. Neutrophil extracellular traps in fungal infection. Semin. Cell Dev. Biol. 2019, 89, 47-57. [CrossRef]

29. Abi Abdallah, D.S.A.; Lin, C.; Ball, C.J.; King, M.R.; Duhamel, G.E.; Denkers, E.Y. Toxoplasma gondii triggers release of human and mouse neutrophil extracellular traps. Infect. Immun. 2012, 80, 768-777. [CrossRef]

30. Reichel, M.; Muñoz-Caro, T.; Sanchez Contreras, G.; Rubio García, A.; Magdowski, G.; Gärtner, U.; Taubert, A.; Hermosilla, C. Harbour seal (Phoca vitulina) PMN and monocytes release extracellular traps to capture the apicomplexan parasite Toxoplasma gondii. Dev. Comp. Immunol. 2015, 50, 106-115. [CrossRef]

31. Yildiz, K.; Gokpinar, S.; Gazyagci, A.N.; Babur, C.; Sursal, N.; Azkur, A.K. Role of NETs in the difference in host susceptibility to Toxoplasma gondii between sheep and cattle. Vet. Immunol. Immunopathol. 2017, 189, 1-10. [CrossRef] [PubMed]

32. Imlau, M.; Conejeros, I.; Muñoz-Caro, T.; Zhou, E.; Gärtner, U.; Ternes, K.; Taubert, A.; Hermosilla, C. Dolphin-derived NETosis results in rapid Toxoplasma gondii tachyzoite ensnarement and different phenotypes of NETs. Dev. Comp. Immunol. 2020, 103, 103527. [CrossRef] [PubMed]

33. Villagra-Blanco, R.; Silva, L.M.R.; Conejeros, I.; Taubert, A.; Hermosilla, C. Pinniped- and Cetacean-Derived ETosis Contributes to Combating Emerging Apicomplexan Parasites (Toxoplasma gondii, Neospora caninum) Circulating in Marine Environments. Biology (Basel) 2019, 8, 12. [CrossRef] [PubMed]

34. Yildiz, K.; Gokpinar, S.; Sursal, N.; Babur, C.; Ozen, D.; Azkur, A.K. Extracellular Trap Formation by Donkey Polymorphonuclear Neutrophils Against Toxoplasma gondii. J. Equine Vet. Sci. 2019, 73, 1-9. [CrossRef]

35. Wei, Z.; Wang, Z.; Liu, X.; Wang, C.; Han, Z.; Wu, D.; Zhang, Y.; Zhang, X.; Yang, Z.; Liu, Q. Toxoplasma gondii Triggers Neutrophil Extracellular Traps Release in Dogs. Front. Cell. Infect. Microbiol. 2020, 10, 429. [CrossRef]

36. Lacerda, L.C.; dos Santos, J.L.; Wardini, A.B.; da Silva, A.N.; Santos, A.G.; Silva Freire, H.P.; dos Anjos, D.O.; Romano, C.C.; Mendes, É.A.; Munhoz, A.D. Toxoplasma gondii induces extracellular traps release in cat neutrophils. Exp. Parasitol. 2019, 207, 107770. [CrossRef]

37. Gomes, A.F.; Guimares, E.V.; Carvalho, L.; Correa, J.R.; Mendonça-Lima, L.; Barbosa, H.S. Toxoplasma gondii down modulates cadherin expression in skeletal muscle cells inhibiting myogenesis. BMC Microbiol. 2011, 11, 110. [CrossRef]

38. Guimarães, E.V.; de Carvalho, L.; Barbosa, H.S. Interaction and cystogenesis of Toxoplasma gondii within skeletal muscle cells in vitro. Mem. Inst. Oswaldo Cruz 2009, 104, 170-174. [CrossRef]

39. Kenny, E.F.; Herzig, A.; Krüger, R.; Muth, A.; Mondal, S.; Thompson, P.R.; Brinkmann, V.; von Bernuth, H.; Zychlinsky, A. Diverse stimuli engage different neutrophil extracellular trap pathways. Elife 2017, 6, e24437. [CrossRef]

40. Guimarães-Costa, A.B.; Nascimento, M.T.C.; Froment, G.S.; Soares, R.P.P.; Morgado, F.N.; Conceição-Silva, F.; Saraiva, E.M. Leishmania amazonensis promastigotes induce and are killed by neutrophil extracellular traps. Proc. Natl. Acad. Sci. USA 2009, 106, 6748-6753. [CrossRef]

41. Morgado, F.N.; Nascimento, M.T.; Saraiva, E.M.; de Oliveira-Ribeiro, C.; Madeira, M.; da Costa-Santos, M.; Vasconcellos, E.C.; Pimentel, M.I.; Rosandiski Lyra, M.; Schubach, A.; et al. Are neutrophil extracellular traps playing a role in the parasite control in active American tegumentary leishmaniasis lesions? PLoS ONE 2015, 10, e0133063. [CrossRef] [PubMed] 
42. De Menezes, J.P.; Saraiva, E.M.; Da Rocha-Azevedo, B. The site of the bite: Leishmania interaction with macrophages, neutrophils and the extracellular matrix in the dermis. Parasit. Vectors 2016, 9, 1-8. [CrossRef] [PubMed]

43. Wardini, A.B.; Guimarães-Costa, A.B.; Nascimento, M.T.C.; Nadaes, N.R.; Danelli, M.G.M.; Mazur, C.; Benjamin, C.F.; Saraiva, E.M.; Pinto-da-Silva, L.H. Characterization of neutrophil extracellular traps in cats naturally infected with feline leukemia virus. J. Gen. Virol. 2010, 91, 259-264. [CrossRef] [PubMed]

44. De Souza-Vieira, T.; Guimarães-Costa, A.; Rochael, N.C.; Lira, M.N.; Nascimento, M.T.; Lima-Gomez, P.d.S.; Mariante, R.M.; Persechini, P.M.; Saraiva, E.M. Neutrophil extracellular traps release induced by Leishmania: Role of PI3K $\gamma$, ERK, PI3Ko, PKC, and [Ca ${ }^{2+}$ ]. J. Leukoc. Biol. 2016, 100, 801-810. [CrossRef]

45. Metz, B.; Kersten, G.F.A.; Baart, G.J.E.; De Jong, A.; Meiring, H.; Ten Hove, J.; Van Steenbergen, M.J.; Hennink, W.E.; Crommelin, D.J.A.; Jiskoot, W. Identification of formaldehyde-induced modifications in proteins: Reactions with insulin. Bioconjug. Chem. 2006, 17, 815-822. [CrossRef]

46. Bliss, S.K.; Gavrilescu, L.C.; Alcaraz, A.; Denkers, E.Y. Neutrophil depletion during Toxoplasma gondii infection leads to impaired immunity and lethal systemic pathology. Infect. Immun. 2001, 69, 4898-4905. [CrossRef]

47. Del Rio, L.; Bennouna, S.; Salinas, J.; Denkers, E.Y. CXCR2 deficiency confers impaired neutrophil recruitment and increased susceptibility during Toxoplasma gondii infection. J. Immunol. 2001, 167, 6503-6509. [CrossRef]

48. Biswas, A.; French, T.; Düsedau, H.P.; Mueller, N.; Riek-Burchardt, M.; Dudeck, A.; Bank, U.; Schüler, T.; Dunay, I.R. Behavior of neutrophil granulocytes during Toxoplasma gondii infection in the central nervous system. Front. Cell. Infect. Microbiol. 2017, 7, 259. [CrossRef]

49. Zhou, E.; Silva, L.M.R.; Conejeros, I.; Velásquez, Z.D.; Hirz, M.; Gärtner, U.; Jacquiet, P.; Taubert, A.; Hermosilla, C. Besnoitia besnoiti bradyzoite stages induce suicidal- and rapid vital-NETosis. Parasitology 2020, 147, 401-409. [CrossRef]

50. Gavrilescu, L.C.; Denkers, E.Y. IFN-gamma overproduction and high level apoptosis are associated with high but not low virulence Toxoplasma gondii infection. J. Immunol. 2001, 167, 902-909. [CrossRef]

51. Morisaki, J.H.; Heuser, J.E.; Sibley, L.D. Invasion of Toxoplasma gondii occurs by active penetration of the host cell. J. Cell Sci. 1995, 108, 2457-2464.

52. Zhao, Y.; Marple, A.H.; Ferguson, D.J.P.; Bzik, D.J.; Yap, G.S. Avirulent strains of Toxoplasma gondii infect macrophages by active invasion from the phagosome. Proc. Natl. Acad. Sci. USA 2014, 111, 6437-6442. [CrossRef] [PubMed]

53. Hakkim, A.; Fuchs, T.A.; Martinez, N.E.; Hess, S.; Prinz, H.; Zychlinsky, A.; Waldmann, H. Activation of the Raf-MEK-ERK pathway is required for neutrophil extracellular trap formation. Nat. Chem. Biol. 2011, 7, 75-77. [CrossRef]

54. Schauer, C.; Janko, C.; Munoz, L.E.; Zhao, Y.; Kienhöfer, D.; Frey, B.; Lell, M.; Manger, B.; Rech, J.; Naschberger, E.; et al. Aggregated neutrophil extracellular traps limit inflammation by degrading cytokines and chemokines. Nat. Med. 2014, 20, 511-517. [CrossRef]

55. Muñoz-Caro, T.; Rubio, M.C.R.; Silva, L.M.R.; Magdowski, G.; Gärtner, U.; McNeilly, T.N.; Taubert, A.; Hermosilla, C. Leucocyte-derived extracellular trap formation significantly contributes to Haemonchus contortus larval entrapment. Parasit. Vectors 2015, 8, 1-12. [CrossRef] [PubMed]

56. Hussain, Q.A. Neutrophil Extracellular Traps: As Antimicrobial Peptides. Oral Rehabil. Dent. 2019, 1-9. [CrossRef]

57. Storisteanu, D.M.L.; Pocock, J.M.; Cowburn, A.S.; Juss, J.K.; Nadesalingam, A.; Nizet, V.; Chilvers, E.R. Evasion of neutrophil extracellular traps by respiratory pathogens. Am. J. Respir. Cell Mol. Biol. 2017, 56, 423-431. [CrossRef] [PubMed]

58. Guimarães-Costa, A.B.; De Souza-Vieira, T.S.; Paletta-Silva, R.; Freitas-Mesquita, A.L.; Meyer-Fernandes, J.R.; Saraiva, E.M. 3'-nucleotidase/nuclease activity allows Leishmania parasites to escape killing by neutrophil extracellular traps. Infect. Immun. 2014, 82, 1732-1740. [CrossRef]

59. Tran, T.M.; MacIntyre, A.; Hawes, M.; Allen, C. Escaping Underground Nets: Extracellular DNases Degrade Plant Extracellular Traps and Contribute to Virulence of the Plant Pathogenic Bacterium Ralstonia solanacearum. PLoS Pathog. 2016, 12, e1005686. [CrossRef]

60. Fuchs, T.A.; Abed, U.; Goosmann, C.; Hurwitz, R.; Schulze, I.; Wahn, V.; Weinrauch, Y.; Brinkmann, V.; Zychlinsky, A. Novel cell death program leads to neutrophil extracellular traps. J. Cell Biol. 2007, 176, 231-241. [CrossRef]

61. Papayannopoulos, V.; Metzler, K.D.; Hakkim, A.; Zychlinsky, A. Neutrophil elastase and myeloperoxidase regulate the formation of neutrophil extracellular traps. J. Cell Biol. 2010, 191, 677-691. [CrossRef] [PubMed] 
62. Li, P.; Li, M.; Lindberg, M.R.; Kennett, M.J.; Xiong, N.; Wang, Y. PAD4 is essential for antibacterial innate immunity mediated by neutrophil extracellular traps. J. Exp. Med. 2010, 207, 1853-1862. [CrossRef] [PubMed]

63. Lewis, H.D.; Liddle, J.; Coote, J.E.; Atkinson, S.J.; Barker, M.D.; Bax, B.D.; Bicker, K.L.; Bingham, R.P.; Campbell, M.; Chen, Y.H.; et al. Inhibition of PAD4 activity is sufficient to disrupt mouse and human NET formation. Nat. Chem. Biol. 2015, 11, 189-191. [CrossRef] [PubMed]

64. Burgos, R.A.; Conejeros, I.; Hidalgo, M.A.; Werling, D.; Hermosilla, C. Calcium influx, a new potential therapeutic target in the control of neutrophil-dependent inflammatory diseases in bovines. Vet. Immunol. Immunopathol. 2011, 143, 1-10. [CrossRef] [PubMed]

65. Conejeros, I.; Patterson, R.; Burgos, R.A.; Hermosilla, C.; Werling, D. Induction of reactive oxygen species in bovine neutrophils is CD11b, but not dectin-1-dependent. Vet. Immunol. Immunopathol. 2011, 139, 308-312. [CrossRef]

66. Vanhaesebroeck, B.; Guillermet-Guibert, J.; Graupera, M.; Bilanges, B. The emerging mechanisms of isoform-specific PI3K signalling. Nat. Rev. Mol. Cell Biol. 2010, 11, 329-341. [CrossRef]

67. Condliffe, A.M.; Davidson, K.; Anderson, K.E.; Ellson, C.D.; Crabbe, T.; Okkenhaug, K.; Vanhaesebroeck, B.; Turner, M.; Webb, L.; Wymann, M.P.; et al. Sequential activation of class IB and class IA PI3K is important for the primed respiratory burst of human but not murine neutrophils. Blood 2005, 106, 1432-1440. [CrossRef]

68. Parker, H.; Dragunow, M.; Hampton, M.B.; Kettle, A.J.; Winterbourn, C.C. Requirements for NADPH oxidase and myeloperoxidase in neutrophil extracellular trap formation differ depending on the stimulus. J. Leukoc. Biol. 2012, 92, 841-849. [CrossRef]

Publisher's Note: MDPI stays neutral with regard to jurisdictional claims in published maps and institutional affiliations. 